\title{
Mechanical Strength Study on C\&D Aggregates Replaced Concrete
}

\author{
S. Suchithra ${ }^{1, a}$ and S. Jayashree ${ }^{2, b^{*}}$ \\ ${ }^{1}$ Associate Professor, Department of Civil Engineering, Kongu Engineering College, Erode, \\ Tamilnadu, India \\ ${ }^{2} P G$ Student, Department of Civil Engineering, Kongu Engineering College, Erode, Tamilnadu, \\ India \\ asuchithra.civil@kongu.edu, bjayashreesiva22@gmail.com
}

\begin{abstract}
Keywords: Recycled Coarse Aggregates, Accelerated Steam Curing, Water Absorption, Construction and Demolition Waste
\end{abstract}

\begin{abstract}
Recycled concrete was produced to overcome the problem of disposal of construction and demolition waste and lack of availability of natural materials. To improve the characteristics of recycled concrete, new treatments and suggestions were given by the researchers. This paper investigates the compressive strength of recycled aggregate concrete having the replacement of 0 , $30,40,50 \& 60 \%$ recycled coarse aggregates. The compressive strength of recycled concrete in water curing is compared with steam curing. The compressive strength of concrete is not much affected because of the use of large size recycled aggregates. The use of saturated dried surface large size recycled aggregates improves the strength of concrete.
\end{abstract}

\section{Introduction}

Day by day technology and innovations were improving, which helps mankind to save their energy. On the other side, the originality of the materials was becoming down. To replace natural products, many artificial products were introduced by mankind. Likewise, the lack of availability of natural materials was replaced by recycled materials. Generally, these recycled materials don't provide the $100 \%$ originality and purity of the corresponding natural materials. By implementing some methods, the recycled materials shall meet the properties of natural materials closely. The recycling process will be carried out using the waste materials. This process also helps to reduce the disposal of wastes. In this way, Construction and Demolition Waste (C\&DW) is one of the major wastes carried out for disposal regularly in the disposal site areas [1]. Some of these wastes are used as embankments, landfills, road fills. But the quantity of these wastes cannot be reduced greatly. To overcome the problem of lack of availability of natural materials and reduction of disposal wastes, the production of recycled concrete is the better solution. The recycled concrete had existed for research work in 90 's, but for the usage in real-time structures till now it is not boomed. The main reason is the lack of confidence among the people in the recycled materials[2]. Recycled concrete shall be produced by adding or replacing one or more materials in the concrete. The use of recycled materials is more if the replacement is carried out in the coarse aggregates other than the replacement in cement or fine aggregates. Also, the replacement of natural coarse aggregates with recycled coarse aggregates provides better results [3]. Many researchers suggested that the natural coarse and fine aggregates in the concrete shall be replaced with $25-30 \%$ of the C\&D waste, which will not provide the greater difference in the strength aspects of the conventional concrete [4-6]. But to replace more than the suggested quantity, some of the treatments should be carried out for the recycled materials. The main drawback for the strength 
loss in the recycled coarse aggregate concrete (RCAC) is the attached mortar of recycled materials [7]. Hence the use of well-washed recycled materials improves the characteristics of the recycled concrete [8]. This paper investigates the workability and compressive strength of the washed RCAC. Also, the compressive strength behaviour of recycled concrete with water curing and accelerated steam chamber curing is compared.

\section{Materials}

\section{Cement}

The type of cement used for this study is the Ordinary Portland Cement (grade 53).

\section{Fine aggregates}

The fine aggregates obtained from the river sand having the size of $4.75 \mathrm{~mm}$ sieve passed are used.

\section{Coarse aggregates}

The well-graded natural aggregates are obtained from the quarry. The recycled aggregates that are obtained from the concrete laboratory wastes shown in fig. 1 and the demolition waste of residential buildings. These wastes are crushed using the hammer and heavy materials to separate the aggregates. The use of large size recycled aggregates doesn't affect the strength properties greatly [9]. Hence, the size of the recycled aggregates used in the concrete mix is passed in a $20 \mathrm{~mm}$ sieve and retained in a $12.5 \mathrm{~mm}$ sieve. The attached mortar and dust are removed partially.

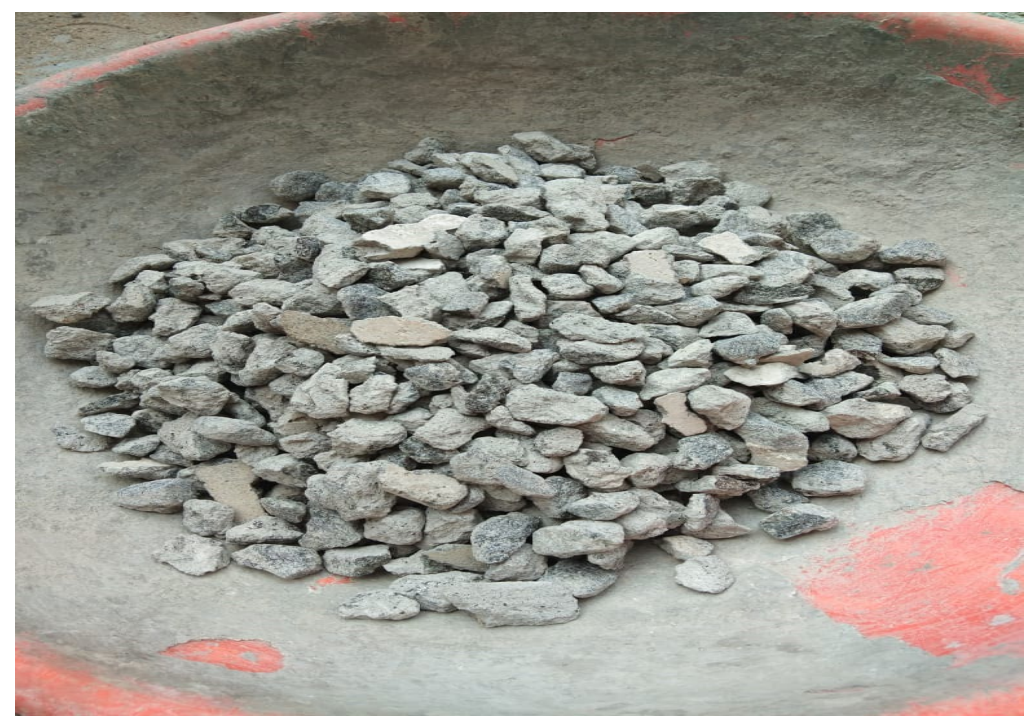

Fig.1 Crushed recycled coarse aggregates

\section{Superplasticizer}

The grade of concrete adopted was M30. Hence as per IS 10262:2019, the superplasticizer (sp) should be used for a high grade of concrete [10]. The sp used in this study was a polycarboxylic ether-based superplasticizer.

\section{Concrete Mixture}

Five different concrete mix was prepared, they are conventional concrete $(\mathrm{CC})$, recycled aggregate concrete with the replacement of 30\% natural aggregates (RAC-1), recycled aggregate concrete with replacement of $40 \%$ natural aggregates (RAC-2), recycled aggregate concrete with $50 \%$ recycled aggregates (RAC-3), recycled aggregate concrete with $60 \%$ recycled aggregates 
(RAC-4). The hand mix is carried out for concrete. The adopted Water-Cement ratio is 0.4. The coarse aggregates were added in saturated dried surface condition, hence the amount of water to be used for all the mix is the same. The concrete mix proportion per cubic meter is tabulated in Table.1.

Table.1 - Concrete mix proportion

\begin{tabular}{|c|c|c|c|c|c|c|}
\hline Description & $\begin{array}{c}\text { Cement } \\
\left(\mathrm{kg} / \mathrm{m}^{3}\right)\end{array}$ & $\begin{array}{c}\text { Natural } \\
\text { coarse } \\
\text { aggregates } \\
\left(\mathrm{kg} / \mathrm{m}^{3}\right)\end{array}$ & $\begin{array}{c}\text { Recycled } \\
\text { coarse } \\
\text { aggregates } \\
\left(\mathrm{kg} / \mathrm{m}^{3}\right)\end{array}$ & $\begin{array}{c}\text { Fine } \\
\text { aggregates } \\
\left(\mathrm{kg} / \mathrm{m}^{3}\right)\end{array}$ & $\begin{array}{c}\text { W/C } \\
\text { ratio }\end{array}$ & $\begin{array}{c}\text { Superplasticizer } \\
\left(\mathrm{kg} / \mathrm{m}^{3}\right)\end{array}$ \\
\hline CC & 415 & 1049.3 & 0 & 852.08 & 0.4 & 4.12 \\
\hline RAC-1 & 415 & 734.51 & 314.79 & 852.08 & 0.4 & 4.12 \\
\hline RAC-2 & 415 & 629.58 & 419.72 & 852.08 & 0.4 & 4.12 \\
\hline RAC-3 & 415 & 524.65 & 524.65 & 852.08 & 0.4 & 4.12 \\
\hline RAC-4 & 415 & 419.72 & 629.58 & 852.08 & 0.4 & 4.12 \\
\hline
\end{tabular}

\section{Test of Coarse aggregates}

\section{Water absorption test}

The test is carried out between the 4 different coarse aggregates. Natural coarse aggregates - NA, recycled coarse aggregates procured from concrete laboratory - RAL, recycled coarse aggregates procured from the demolition wastes - RAD, a combination of recycled coarse aggregates procured from concrete laboratory and demolition waste - CRA were tested.

Specific gravity test

The specific gravity test on natural aggregates and recycled coarse aggregates - CRA wereconducted.

\section{Test on Concrete}

\section{Workability test}

The fresh concrete test is carried out with a slump cone. A slump cone test was carried out for all five concrete mixes.

\section{Compressive strength test}

The test is carried out using a $150 \times 150 \times 150 \mathrm{~mm}$ cube. Curing of concrete is carried out in twoways - water curing and accelerated steam curing. The 7-day and 28-day compressive strength was tested. And the steam curing is carried in the accelerated steam curing chamber at $100^{\circ} \mathrm{C}$ for 3 hours.

\section{Results and Discussion}

Tests on Coarse aggregates

The water absorption rate of RCA's was greater than the natural coarse aggregates. Compared to all other aggregates the combined recycled coarse aggregates - CRA absorbs more water. The water absorption capacity is more in recycled aggregates due to the presence of attached mortar and pores. This absorption rate of aggregates may affect the concrete at later ages. Table. 2 shows 
the water absorption rate and a specific gravity of all four types of aggregates. The specific gravity of natural and recycled aggregates does not show much variation.

Table. 2 - Water absorption and a specific gravity of samples

\begin{tabular}{|c|c|c|}
\hline Description & Water absorption rate & Specific gravity \\
\hline NA & 1.96 & 2.79 \\
\hline RAL & 8.42 & 2.65 \\
\hline RAD & 6.38 & 2.69 \\
\hline CRA & 9.67 & 2.67 \\
\hline
\end{tabular}

\section{Workability test}

The result of the workability test on all five concrete mixes was shown in Fig.2. Since all the aggregates are allowed to absorb enough water before mixing, the workability of concrete is not affected greatly. The workability of the conventional concrete is good enough for casting. Likewise, the workability of other concrete mixes does not vary much.

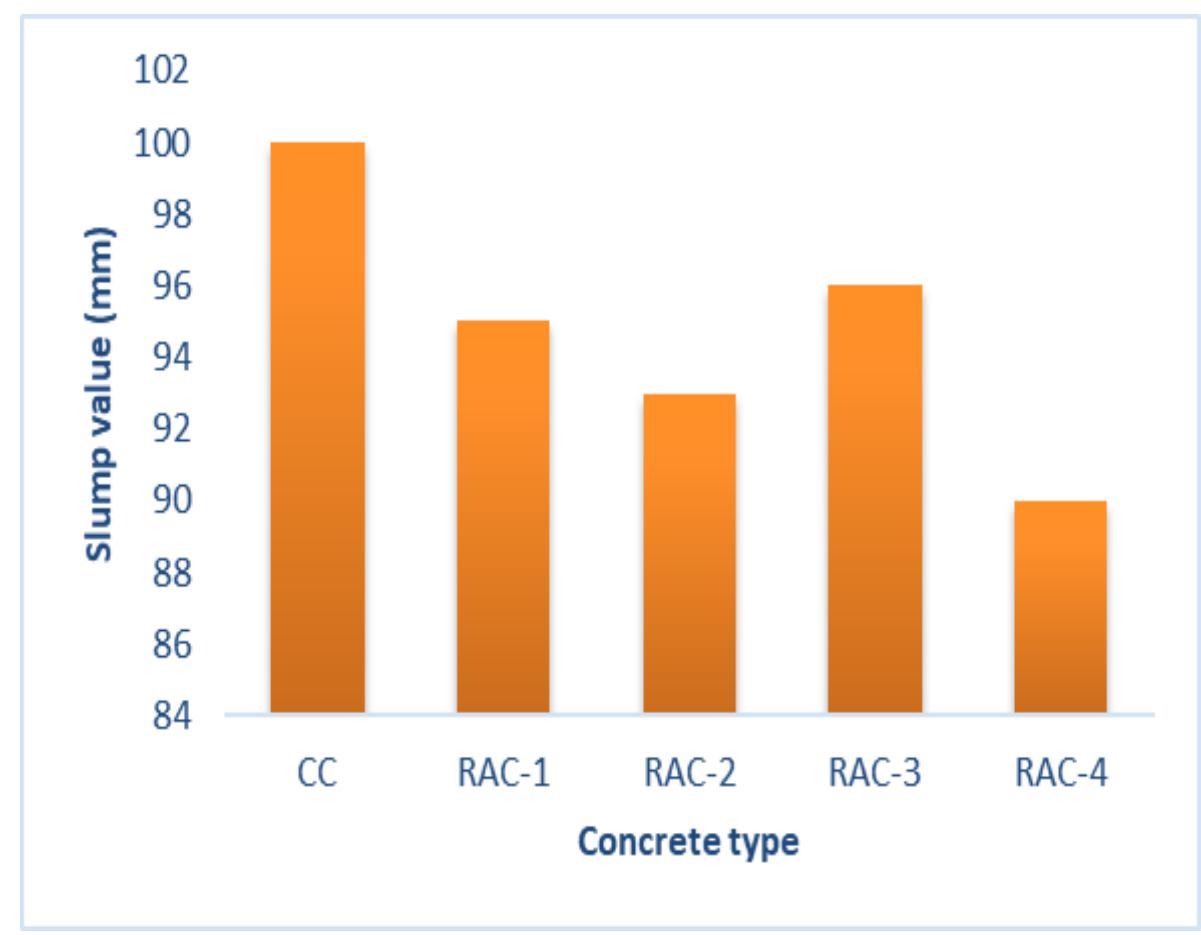

Fig.2 - Workability of conventional and recycled concrete

\section{Compressive strength}

The 7-day and 28-day compressive strength of the different types of concrete are shown in Fig.3. 


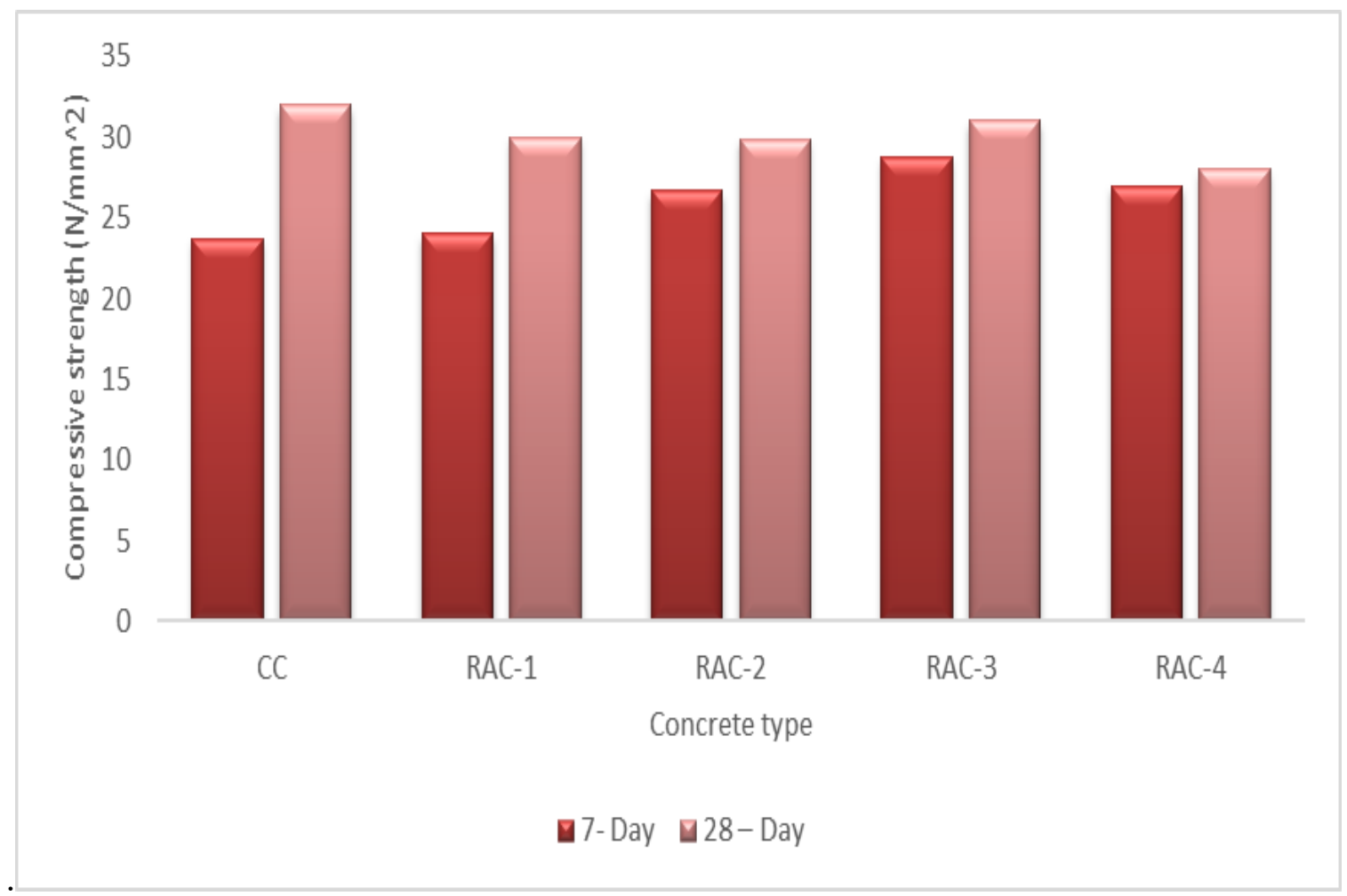

Fig.3-Compressive strength of concrete

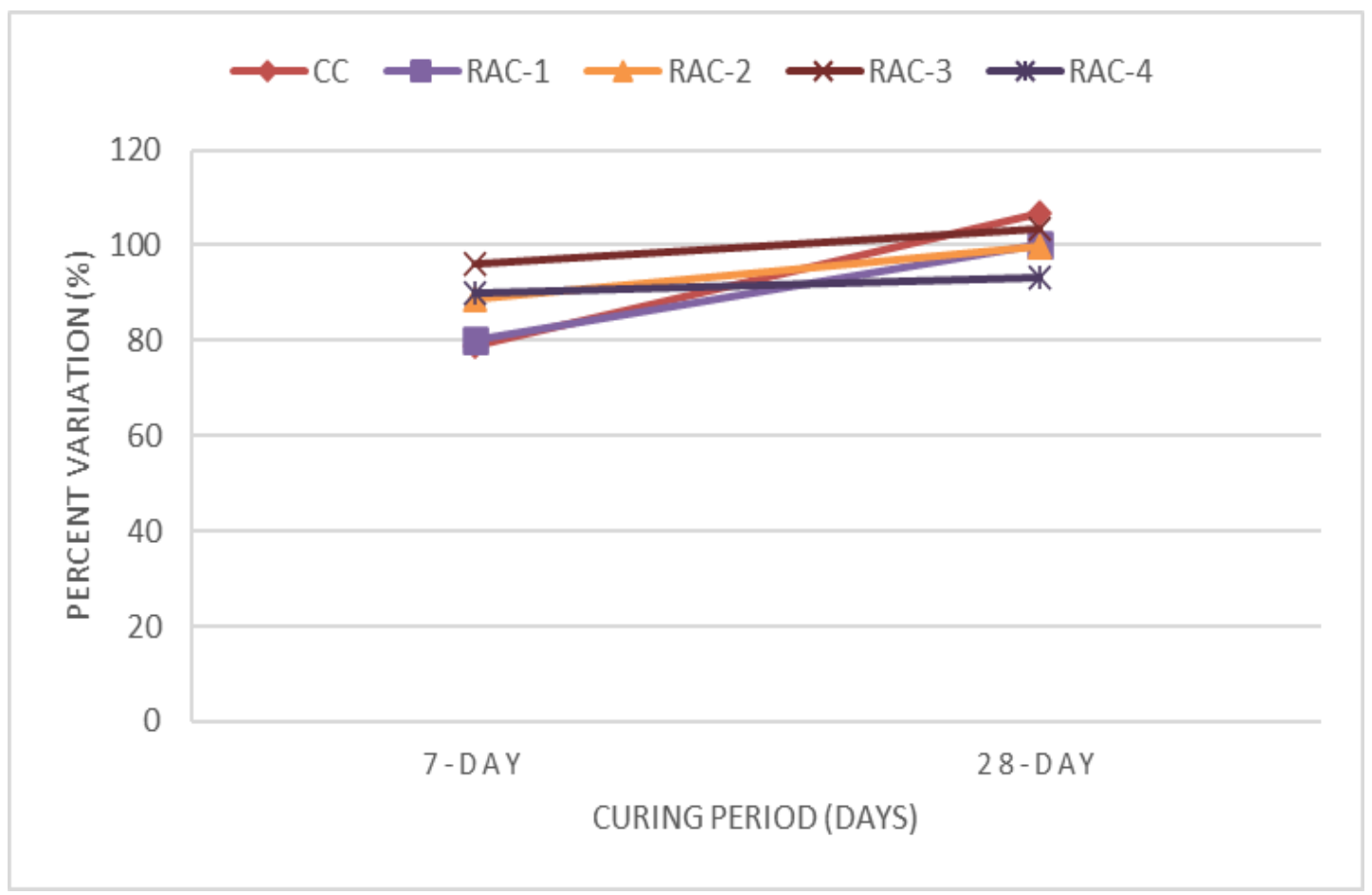

Fig.4-Comparison between 7-d and 28-d compression strength 


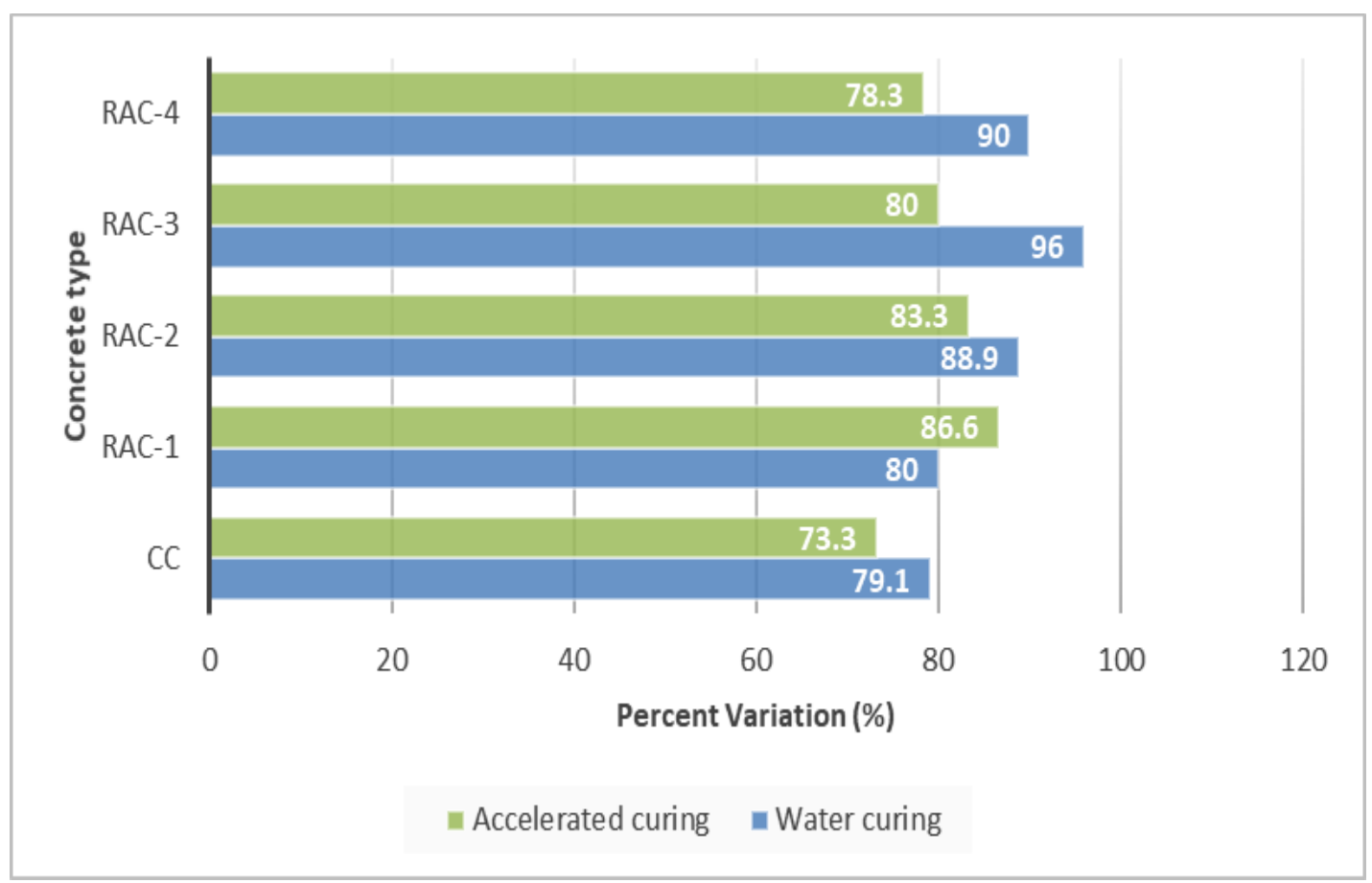

Fig.5 - Comparison between 7-d and accelerated curing compressive strength

From the above graph, it is well-known that the strength of 7-day curing and accelerated curing provides almost the same results. Through accelerated steam curing for 3 hours, the concrete shall attain 7-day compressive strength. Changes had been observed in 28-day compressive strength, when compared with 7-day and accelerated curing. The strength of conventional concrete achieved its 28-day compressive strength. As the curing period increases, the strength of all types of concrete is increased. Also, the compressive strength of concrete generally decreases with an increase in the replacement percent. Here the compressive strength of the recycled concrete increases with an increase in replacement percent to 50\%. In RAC-4, the compressive strength decreases again. From fig.4, it is observed that the strength of conventional concrete increases from $79 \%$ to $106 \%$ as the curing period increases. Whereas, RAC-1, RAC-2, RAC-3 and RAC-4 shows the strength variation 80 to $100 \%, 88.9$ to $99.6 \%, 96$ to $103.3 \%$ and 90 to $93.3 \%$ respectively. Until the RAC-3 concrete mix, the concrete achieves its target mean strength. Compared to accelerated curing, the water curing compressive strength of concrete provides greater strength as shown in fig.5. But generally, steam curing provides better results if the curing period is increased. Because of less duration for curing, all the concrete mix attains the 7-day compressive strength nearly. The 50\% replacement of RCA's in the concrete attains the target strength i.e., attains the strength of conventional concrete. Fig. 6 exhibits the crack that propagated in the recycled aggregate concrete after the compression test. 


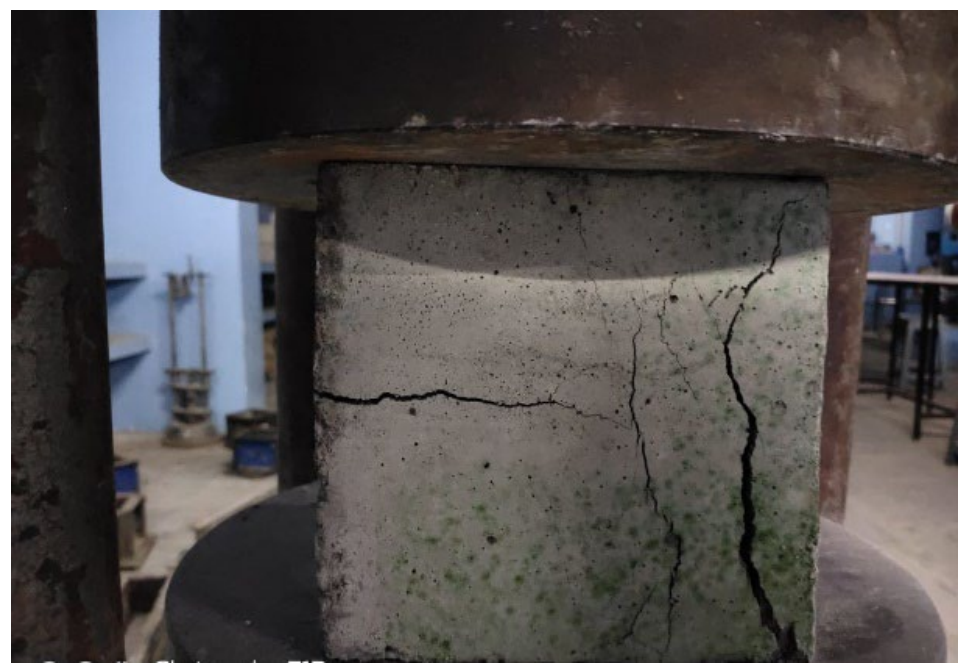

Fig.6-Compression test on Concrete

\section{Conclusion}

From the experimental investigation on RCAC and RCA's following conclusions were made,

- Due to the presence of more voids, the water absorption rate is greater in the recycled aggregates than the natural aggregates.

- The removal of specks of dust and attached mortar of recycled aggregates improves the properties of aggregates.

- The workability of concrete does not affect greatly because of the use of a superplasticizer.

- The use of large-size saturated dried-surface recycled aggregates helps to improve the compressive strength of concrete and also $50 \%$ replacement shall be carried out. Replacement of natural aggregates more than $50 \%$ reduces the strength of concrete.

- For non-structural applications, more than 50\% replacement shall be done. For structural applications, $50 \%$ replacement shall be carried out along with the addition of sp and the use of large size recycled aggregates.

- Since the usage of recycled aggregates is more, it is better to implement mechanical equipment to separate the recycled aggregates from Demolition wastes and Concrete wastes.

\section{References}

[1] M.R. Ponnada, K. P, Construction and Demolition Waste Management - A Review, Int. J. Adv. Sci. Technol. 84 (2015) 19-46. https://doi.org/10.14257/ijast.2015.84.03.

[2] R. V. Silva, R. Neves, J. De Brito, R.K. Dhir, Carbonation behaviour of recycled aggregate concrete, Cem. Concr. Compos. 62 (2015) 22-32.

https://doi.org/10.1016/j.cemconcomp.2015.04.017.

[3] C. Liang, H. Ma, Y. Pan, Z. Ma, Z. Duan, Z. He, Chloride permeability and the caused steel corrosion in the concrete with carbonated recycled aggregate, Constr. Build. Mater. 218 (2019) 506-518. https://doi.org/10.1016/j.conbuildmat.2019.05.136.

[4] B. Cantero, I.F. Sáez del Bosque, A. Matías, M.I. Sánchez de Rojas, C. Medina, Inclusion of construction and demolition waste as a coarse aggregate and a cement addition in structural concrete design, Arch. Civ. Mech. Eng. 19 (2019) 1338-1352.

https://doi.org/10.1016/j.acme.2019.08.004.

[5] A. Juan-Valdés, D. Rodríguez-Robles, J. García-González, M.I. Sánchez de Rojas Gómez, M. 
Ignacio Guerra-Romero, N. De Belie, J.M. Morán-del Pozo, Mechanical and microstructural properties of recycled concretes mixed with ceramic recycled cement and secondary recycled aggregates. A viable option for future concrete, Constr. Build. Mater. (2020).

https://doi.org/10.1016/j.conbuildmat.2020.121455.

[6] Z. Ma, W. Li, H. Wu, C. Cao, Chloride permeability of concrete mixed with activity recycled powder obtained from C\&D waste, Constr. Build. Mater. 199 (2019) 652-663. https://doi.org/10.1016/j.conbuildmat.2018.12.065.

[7] A. Adessina, A. Ben Fraj, J.F. Barthélémy, C. Chateau, D. Garnier, Experimental and micromechanical investigation on the mechanical and durability properties of recycled aggregates concrete, Cem. Concr. Res. 126 (2019) 105900. https://doi.org/10.1016/j.cemconres.2019.105900.

[8] L. Restuccia, C. Spoto, G.A. Ferro, J.M. Tulliani, Recycled Mortars with C\&D Waste, Procedia Struct. Integr. 2 (2016) 2896-2904. https://doi.org/10.1016/j.prostr.2016.06.362.

[9] R. Rao, Q. Deng, J. Fu, C. Liu, X. Ouyang, Y. Huang, Improvement of mechanical strength of recycled blend concrete with secondary vibrating approach, Constr. Build. Mater. 237 (2020) 117661. https://doi.org/10.1016/j.conbuildmat.2019.117661.

[10] Bureau of Indian Standards (BIS), Concrete Mix Proportioning- Guidelines, Bur. Indian Stand. Second Rev (2019) 1-40. 